\title{
E-cigarette Use Is Associated with Non-prescribed Medication Use in Adults: Results from the PATH Survey
}

\author{
Kathryn Bentivegna, MPH, Nkiruka C. Atuegwu, PhD, Cheryl Oncken, MD, MPH, \\ Erin L. Mead, PhD, Mario F. Perez, MD, MPH, and Eric M. Mortensen, MD, MSc
}

University of Connecticut Medical Center, Farmington, CT, USA.

J Gen Intern Med 34(10): 1995-7

DOI: $10.1007 / \mathrm{s} 11606-019-05093-5$

(c) Society of General Internal Medicine 2019

\section{INTRODUCTION}

Electronic cigarettes ("e-cigs") are devices designed to simulate smoking cigarettes by heating a liquid that usually contains glycerine, propylene glycol, flavors, and nicotine, a behavior commonly known as "vaping." 1 E-cig use has significantly increased in popularity during the last decade, particularly among adolescents and young adults. ${ }^{2}$ Although they have been promoted as a safer alternative to smoking conventional cigarettes, e-cigs are not without harm, ${ }^{1}$ and additionally, recent reports suggest that e-cigs could also be used as illicit drug delivery systems. ${ }^{3}$ This is highly relevant as e-cig users have reported other high-risk behavior when compared with subjects who do not use them, including alcohol, tobacco, and marijuana use. 4,5

The purpose of this study was to examine the association between e-cig use and a participant's report of nonprescription use of controlled prescription medications, including $^{1}$ pain killers, sedatives or tranquilizers, and/or ${ }^{2}$ the stimulants methylphenidate (Ritalin $\AA$ ) and dextroamphetamine/ amphetamine (Adderall@) within a nationally representative sample of adults. Our hypothesis was that regular use of ecigs would be associated with a higher reporting of nonprescription drug use.

\section{METHODS}

Publicly available data from the first three waves of the Population Assessment of Tobacco and Health (PATH) study were used. ${ }^{6}$ Wave 1 respondents were eligible to participate in wave 2 and 3 interviews if they continued living in the USA and were not incarcerated.

We included adults $\geq 18$ years who completed interviews for waves $1-3(N=23,670)$. Current e-cig use was defined as daily or some-day use of e-cigs in wave 1 . We used logistic regression to examine the association between current e-

$\overline{\text { Presentations This work was presented at the } 2019 \text { National Society of }}$ General Internal Medicine Annual meeting.

Published online June 12, 2019 cigarette use in wave 1 and use of diverted prescription drugs including ${ }^{1}$ pain killers, sedatives, or tranquilizers and ${ }^{2}$ Ritalin/ Adderall in the last 30 days or last 12 months in waves 2 or 3 , after adjusting for the covariates in Table 1. Replicate weights and balanced repeated replication methods were utilized to account for the complex survey design. All analyses were conducted using $\mathrm{R}$ version 3.4.2.

\section{RESULTS}

We compared the 2639 current e-cig users to the 21,024 nonusers. Weighted demographics and other characteristics are presented in Table 1. After adjusting for potential confounders, the use of e-cigs was associated with significantly higher use of non-prescribed pain killers, sedatives, or tranquilizers in the last 30 days (odds ratio [OR] 1.30, 95\% confidence interval [CI] 1.14-1.48) and last 12 months (OR 1.31, 95\% CI 1.151.49). Additionally, the use of e-cigs was associated with significantly higher use of non-prescribed Ritalin/Adderall in the last 30 days (OR 1.50, 95\% CI 1.06-2.12) and last 12 months (OR 1.31, 95\% CI 1.01-1.67).

\section{DISCUSSION}

We found that e-cig users have significantly higher odds of non-prescription use of pain killers, sedatives or tranquilizers, and the stimulants Ritalin/Adderall. These findings are consistent with previous research examining other risky behaviors among e-cig users, including alcohol, tobacco, and marijuana use. ${ }^{4,5}$ Although these non-prescribed drugs would have been acquired in pill form, research has found that methamphetamines, Ritalin, opioids, and muscle relaxers can also be dissolved in glycerin, and potentially be vaped in e-cigs. Also, some benzodiazapines come in liquid form which can be vaped if diluted. ${ }^{3}$ This findings suggest that medications could be dissolved and vaped by e-cig users.

In summary, we found an association between e-cig use and the non-prescription use of controlled medications, which adds to the literature on the relationship between e-cig use and risky behavior. A limitation is the possibility of recall bias in the survey. Despite this limitation, clinicians should be aware of this association and assess whether inappropriate use of prescription medications occurs in their patients who 
Table 1 Weighted Demographics and Health History of Adults at Wave 1

\begin{tabular}{|c|c|c|}
\hline & \multirow{2}{*}{$\frac{\text { Not current e-cig user }}{(n=21,024)}$} & \multirow{2}{*}{$\begin{array}{l}\text { Current e-cig user } \\
(n=2639)\end{array}$} \\
\hline & & \\
\hline & $(\%, 95 \% \mathrm{CI})$ & $(\%, 95 \% \mathrm{CI})$ \\
\hline \multicolumn{3}{|l|}{ Age group } \\
\hline 18 to 24 years old & $12.6(12.5-12.7)$ & $21.2(19.6-22.8)$ \\
\hline 25 to 34 years old & $17.3(16.7-17.9)$ & $26.9(24.9-28.9)$ \\
\hline 35 to 44 years old & $16.6(16-17.2)$ & $18.5(16.6-20.4)$ \\
\hline 45 to 54 years old & $18.0(17.4-18.5)$ & $17.2(15.6-18.8)$ \\
\hline 55 to 64 years old & $17.0(16.5-17.6)$ & $11.7(10.2-13.2)$ \\
\hline 65 and older & $18.4(18.2-18.6)$ & $4.4(3.3-5.5)$ \\
\hline \multicolumn{3}{|l|}{ Gender } \\
\hline Male & $47.6(47.4-47.7)$ & $53.0(50.8-55.1)$ \\
\hline \multicolumn{3}{|l|}{ Race } \\
\hline White & $77.8(77.4-78.2)$ & $80.8(79.2-82.4)$ \\
\hline Black & $12.5(12.3-12.7)$ & $9.4(8.2-10.6)$ \\
\hline Other & $9.7(9.5-10.0)$ & $9.8(8.5-11.1)$ \\
\hline Hispanic & $15.2(15.1-15.3)$ & $12.4(10.9-13.9)$ \\
\hline \multicolumn{3}{|l|}{ Highest grade of education } \\
\hline Less than high school & $11.4(11.0-11.8)$ & $12.3(11.0-13.6)$ \\
\hline GED & $4.8(4.4-5.1)$ & $9.5(8.3-10.7)$ \\
\hline High school graduate & $24.1(23.9-24.3)$ & $25.7(23.6-27.8)$ \\
\hline Some college (no degree) or associates degree & $30.7(30.5-30.9)$ & $39.0(36.7-41.3)$ \\
\hline Bachelor's degree or higher & $29.0(28.8-29.2)$ & $13.5(12.3-14.8)$ \\
\hline \multicolumn{3}{|l|}{ Income } \\
\hline Less than $\$ 10,000$ & $13.4(12.8-14.0)$ & $19.8(17.9-21.7)$ \\
\hline$\$ 10,000$ to $\$ 24,999$ & $19.9(19.0-20.8)$ & $26.0(24.0-28.1)$ \\
\hline$\$ 25,000$ to $\$ 49,999$ & $22.7(21.8-23.6)$ & $25.0(23.0-27.1)$ \\
\hline$\$ 50,000$ to $\$ 99,999$ & $25.9(24.9-26.9)$ & $20.5(18.5-22.5)$ \\
\hline 100,000 or more & $18.1(17.1-19.2)$ & $8.7(7.4-9.9)$ \\
\hline \multicolumn{3}{|l|}{ Other exposures } \\
\hline Current established cigarette user & $14.9(14.4-15.5)$ & $70.0(68-71.9)$ \\
\hline Former established cigarette user & $20.5(19.5-21.5)$ & $14.4(12.6-16.1)$ \\
\hline Current hookah user & $3.1(2.9-3.4)$ & $20.0(18.0-22.0)$ \\
\hline Current cigarillos user & $3.5(3.3-3.7)$ & $20.0(18.2-21.8)$ \\
\hline Current pipe user & $0.9(0.8-1.0)$ & $5.4(4.3-6.5)$ \\
\hline Current any oral tobacco use & $3(2.8-3.3)$ & $8.8(7.5-10)$ \\
\hline Current any cigar use & $4.7(4.4-4.9)$ & $20.4(18.6-22.3)$ \\
\hline Alcohol use last 30 days & $50.9(49.2-52.6)$ & $59.1(56.9-61.3)$ \\
\hline Marijuana use last 30 days & $6.6(6.0-7.1)$ & $20.6(18.8-22.5)$ \\
\hline Crack cocaine use last 30 days & $0.4(0.3-0.5)$ & $1.3(0.8-1.8)$ \\
\hline Methamphetamine use last 30 days & $0.2(0.2-0.3)$ & $1.2(0.7-1.7)$ \\
\hline Heroin, inhalants, solvents, or hallucinogens use last 30 days & $0.3(0.2-0.3)$ & $1.0(0.6-1.4)$ \\
\hline \multicolumn{3}{|l|}{$\begin{array}{l}\text { Psychiatric symptoms } \\
\text { Pas }\end{array}$} \\
\hline Felt lonely, depressed, and/or hopeless last 30 days & $13.1(12.4-13.8)$ & $23.3(21.5-25.1)$ \\
\hline Felt anxious, nervous, tense, scared, and/or panicked last 30 days & $15.5(14.8-16.2)$ & $29.3(27.4-31.1)$ \\
\hline Used Ritalin or Adderall last 30 days* & $0.5(0.4-0.6)$ & $3.1(2.3-3.9)$ \\
\hline Used Ritalin or Adderall last 30 days $^{\dagger}$ & $1.0(0.9-1.2)$ & $4.5(3.5-5.6)$ \\
\hline Used Ritalin or Adderall last 12 months $^{\dagger}$ & $2.2(2.0-2.4)$ & $7.6(6.5-8.8)$ \\
\hline Used painkillers, sedatives or tranquilizers last 30 days* & $4.7(4.3-5.1)$ & $10(8.8-11.3)$ \\
\hline Used painkillers, sedatives or tranquilizers last 30 days $^{\dagger}$ & $9.1(8.5-9.7)$ & $17.7(16.3-19.2)$ \\
\hline Used painkillers, sedatives or tranquilizers last 12 months ${ }^{\dagger}$ & $12.5(11.8-13.2)$ & $23.6(21.7-25.5)$ \\
\hline
\end{tabular}

*Wave 1

${ }^{\dagger}$ Wave 2 or 3

use e-cigs. Clinicians need to inform all patients that they should only take medication prescribed to them, use medications as instructed, and not share with others.

Corresponding Author: Eric M. Mortensen, MD, MSc; University of Connecticut Medical Center, Farmington, CT, USA (e-mail: mortensen@uchc.edu).

Funding Dr. Cheryl Oncken receives support from the NIH grants R01CA207491 and R01HD069314. She has also received clinical trial support from Pfizer pharmaceuticals.

\section{Compliance with Ethical Standards:}

Conflict of Interest: Dr. Mortensen has consulted, and provided expert testimony, for Paratek Pharmaceuticals. All remaining authors declare that they do not have a conflict of interest.

\section{REFERENCES}

1. Dinakar C, O'Connor GT. The Health Effects of Electronic Cigarettes. New England Journal of Medicine. 2016;375(14):1372-81.

2. Mirbolouk M, Charkhchi P, Kianoush S, et al. Prevalence and distribution of e-cigarette use among u.s. adults: Behavioral risk factor surveillance system, 2016. Annals of Internal Medicine. 2018;169(7):429-38.

3. Varlet V. Drug Vaping: From the Dangers of Misuse to New Therapeuitic Devices. Toxics 2016; 4(4):29 
4. Cohn A, Villanti A, Richardson A, et al. The association between alcohol, marijuana use, and new and emerging tobacco products in a young adult population. Addict Behav. 2015;48:79-88.

5. Saddleson ML, Kozlowski LT, Giovino GA, et al. Risky behaviors, ecigarette use and susceptibility of use among college students. Drug Alcohol Depend. 2015;149:25-30.
6. Hyland A, Ambrose BK, Conway KP, et al. Design and methods of the Population Assessment of Tobacco and Health (PATH) Study. Tobacco Control. 2017;26(4):371-8.

Publisher's Note Springer Nature remains neutral with regard to jurisdictional claims in published maps and institutional affiliations. 